\title{
Sociedad civil y «crisis de la política»
}

\author{
FERNANDO VALLESPIN \\ Universidad Autónoma de Madrid
}

El presente artículo aborda to que se considera que son algunas de las deficiencias de la teoría contemporánea de la sociedad civil. Para ello pasa brevemente revista a la evolución histórica del concepto, y se presenta una selección de sus definiciones contemporáneas. Todas ellas manifiestan una cierta imposibilidad para contemplar la política si no es desde una polarización dualista Estado-Sociedad, que trata de superarse abriéndose el concepto de sociedad civil a una mayor interrelación entre estos dos polos. Asimismo, se afirma que el recurso a la «sociedad civil» sirve para recomponer en el ámbito de la teoría y resolver de un solo golpe dos de las grandes deficiencias que asolan a las relaciones entre sistema político y sociedad: la ausencia de un sujeto unitario claramente delimitado y el déficit de integración normativa.

Pocos conceptos están hoy tan en boca de los políticos y aparecen tan a menudo en los medios de comunicación o en la literatura especializada como el de «sociedad civil». Pocos guardan también tales dosis de imprecisión e indefinición. Puede que, como ya ha sido observado, ambos fenómenos estén relacionados; que es su misma ambigüedad, su falta de un claro asentamiento en la realidad, lo que le ha permitido tener una presencia tan brillante en la actual percepción de la política (H. Dubiel, 1994). El hecho de que la sociedad civil se haya convertido en una referencia casi totémica tanto para la izquierda como para la derecha, es bien expresivo de su elasticidad semántica. Esta ductilidad del concepto no dice mucho a su favor como instrumento válido para la discusión científico-política, y su utilización abusiva amenaza incluso con hacerlo irrelevante, con convertirlo en un mero y vago estereotipo. Aun así, ino es esto lo que ocurre con casi todos los conceptos políticos? iAcaso no hemos de comenzar siempre nuestra exposición de cualquiera de ellos distinguiendo sus diversos usos en tal o cual autor, haciendo referencia a su evolución histórica, o, en fin, llevándolos a un territurio que nos permita hacerlos operativos? La «socicdad civil» y la pluralidad de concepciones de que va acompañada no iba a estar exenta de estas servidumbres, y aquí no tendremos más remedio también que comenzar con eso que Sartori llama un intellectual house cleaning, con una previa depuración del concepto. Pero no es esto lo que nos va a ocupar en este artículo, al menos de modo directo. Tampoco nos interesa incidir en una «teoría política de la sociedad civil», que por poco ambiciosa que fuere, no podría escaparse de la fuerza gravitatoria del monumental y 
exhaustivo libro de J. Cohen y A. Arato (1992). Nuestro objetivo consiste más bien en llamar la atención sobre diversos fenómenos que creemos que la actual reflexión sobre la sociedad civil ha contribuido a poner de relieve y que afectan a la comprensión básica que tenemos hoy sobre la política. La tesis de la que partimos es que la sociedad civil se ha convertido en un "valor refugio" en un momento de clara crisis de identidad de la política democrática, que su meteórica carrera es un adecuado reflejo de muchas de las perplejidades que asolan a los distintos discursos ideológicos, ya sean éstos de «izquierdas* o de «derechas», en este convulso fin de siglo. Pero que precisamente por eso, la indagación en torno a las causas de su «éxito» en la ciencia y teoría política contemporáneas nos permite obtener una interesante radiografía de los limites de la reflexión política en nuestros días.

Para desarrollar esta idea, y una vez acotado mínimamente el concepto, vamos a concentrarnos en dos síndromes de la política que, a nuestro juicio, ha contribuido a poner de manifiesto la discusión en torno a la sociedad civil. El primero - que a falta de un mejor término hemos calificado como el síndrome de la «mirada codificada»— trata de abundar en un aspecto predominantemente epistemológico: nuestra casi absoluta imposibilidad de comprender la realidad política si no es desde la polarización dualista de Estado-Sociedad. La revitalización de un concepto como el de sociedad civil sería expresiva de esta supuesta incapacidad nuestra para trazar fronteras o «diferencias» novedosas desde la instancia de observación convencional de las ciencias sociales, y apunta a una cierta «crisis de percepción». Las limitaciones de la polarización entre «Estado-Sociedad civil», que sirven para scparar a cntidades casi reificadas de la realidad social, saltan a la vista. No ya sólo por la dificultad de separar ambos conceptos, sino por la misma incapacidad para llegar a un acuerdo sobre las mismas diferenciaciones internas de cada uno de ellos. La primera conclusión provisional a la que habremos de llegar a estos efectos es que dicha percepción dualista no alcanza a nuestra complejidad, y que ello ha permitido comprimir en la referencia a la sociedad civil prácticamente todo lo que no tiene cabida en el concepto de «Estado». Sociedad civil sería entonces un concepto residual, que sólo cobra plausibilidad a partir de su contraste con el fenómeno Estado, pero que por su misma vaguedad y amplitud amenaza con resultar irrelevante.

El segundo síndrome incide ya más directamente sobre los aspectos normativos de la política democrática. En particular sobre la conexión que se establece entre el concepto de sociedad civil como sede de las comunicaciones e interacciones que median entre el individuo y el Estado, y el proceso democrático en un sentido amplio. Lo que aquí se detecta es la clara valoración positiva de que se dota a la supuesta espontaneidad y pluralismo de las actividades que en ella tienen lugar, que contrasta con la propia evaluación del Estado como el ámbito de la burocratización y la rigidez, como un «mal necesario» únicamente justificable desde su respeto y cooperación con esa otra 
esfera de la libre interacción y comunicación de la sociedad civil. Esta valoración, más o menos explícita o larvada en todas las teorías de la sociedad civil, es «sintomática» de un cierto divorcio o, cuando menos, de ciertas dificultades de adaptación entre una sociedad en mutación constante y el correspondiente aparato estatal. Afecta sobre todo al problema de la mediación política, tanto en lo referente a la dimensión de la participación política, cuanto a la misma integración de intereses. Pero es bien expresivo también del proceso de fragmentación social de nuestra sociedad actual, que muy dif́cilmente se deja unificar mediante la hipóstasis de un sujeto democrático unitario, el demos, como asiento de las energías democratizadoras. El recurso a la «sociedad civil» sirve así para recomponer en el ámbito de la teoría y resolver de un solo golpe dos de las grandes deficiencias que asolan a las relaciones entre sistema político y sociedad: la ausencia de un sujeto unitario claramente delimitado y el déficit de integración normativa. La sociedad civil constituiría así un subterfugio a partir del cual la creciente diferenciación y fragmentación del sistema democrático puede ser «representada» dentro de una unidad social.

No es casualidad que el concepto de sociedad civil reverdeciera en los movimientos anteriores a los procesos de transición a la democracia en los países del Este europeo (véase, por ejemplo, Arato, 1981) o que sirviera como criterio explicativo de la misma transición política española (V. Pérez-Díaz, 1987, 1993). De modo más o menos explícito, se da por buena la hipótesis de la falta de adaptación del Estado - autoritario en estos casos-a una sociedad más plural y evolucionada, y se traslada así el protagonismo del cambio a csta última. Esta hipótesis, en sí misma bastante convincente, se hace extensiva, sin embargo, como tal principio de evaluación de la realidad, a «cualquier tipo de Estado». De modo más o menos matizado, casi cualquier teoría de la sociedad civil tiende a reproducir así ese acento valorativo al que antes nos referíamos. $\mathrm{Y}$ el peligro que inmediatamente se detecta no es ya sólo una posible caída en un discurso «anti-estatista», sino en uno pura y llanamente «anti-político». Va de suyo, que las reflexiones que siguen no constituyen más que una primera aproximación a estos problemas, que habrán de requerir en el futuro algo más que este conjunto de reflexiones hilvanadas.

\section{I}

Como venimos diciendo, no es sencillo abordar la cuestión del concepto de sociedad civil de un modo sintético. El mejor punto de partida para penetrar en él nos lo ofrece Ch. Taylor (1995) en su breve artículo sobre el tema, que iremos modificando a lo largo de la exposición para permitir la incorporación de ulteriores matizaciones. Allí este autor distingue entre dos conceptos o «corrientes» en la comprensión de la sociedad civil, que se van a corresponder también, mutatis mutandi, a las dos grandes variaciones que nos encontramos 
de ella en la literatura. Taylor las utiliza para ofrecer una esquemática evolución histórica del concepto, aunque aquí sólo nos interesan de modo puramente analítico ${ }^{1}$. La primera "corriente» o modelo se corresponde a grandes rasgos con la formulación de Locke ( $L$. Stream), con su conocida contraposición entre Estado y sociedad; su visión de que la «sociedad» es algo «previo» o «anterior» al Estado y que, en todo caso, puede cobrar su identidad con independencia de la dimensión política. Presupone la acción de individuos operando libremente en una esfera acotada por los derechos individuales reconocidos por la Constitución, que sirve para delimitar claramente el espacio que separa a las interacciones de los individuos en el mercado $-u$ otros ámbitos «privados»del marco de lo epúblico». Es el modelo tan caro al paleo y neo-liberalismo, que va acompañado de su bien conocida parafernalia conceptual: individualismo atomista, realización individual en la esfera privada, libertad negativa; o, en el otro campo, la visión de la política como mera garantía y protección de la economía de mercado y guiada por el principio de la representación de intereses, pero nunca como instancia de "dirección» de los flujos sociales ${ }^{2}$. En tanto que "teoría» de la sociedad civil, encuentra su manifestación más relevante en la Ilustración escocesa (Ferguson, A. Smith, D. Hume). Aquí civil se identifica ya explícitamente a economic society como esfera de identidad no política, con sus propias lógicas y principios de organización, a la que pronto se suma también el ámbito de la opinión pública como elemento que permite a la comunidad reconocerse como tal en una esfera de mutua y libre interacción. Aun poseyendo una evidente conexión con la política, la opinión pública se caracterizaría por elaborarse totalmente al margen de los canales y espacios públicos de las instituciones estatales (cfr. Taylor, 1995: 216-7).

Esta concepción de la sociedad como caracterizada por tener una identidad pre o no-política no sólo se manifiesta en la hipostatización de la sociedad al ámbito económico, próximo a un «libertarismo» que marginaliza plenamente al Estado. Está presente también en el mismo planteamiento de Marx de anular la dimensión política a favor de la "productiva» o «material», que habría de desembocar en una mera "administración de las cosas» (a este respecto, véase M. Walzer: 1991, 295-6), o en la teoría russeauniana de la autodeterminación del pueblo, que «enguye al Estado en la sociedad en una supuesta voluntad generals (Taylor, 1995: 220).

Un concepto distinto nos lo encontramos en el modelo de Montesquieu (la M.Stream de Taylor), que recupera la antigua idea greco-romana de la esencial identidad entre sociedad y política, y la consiguiente imposibilidad

'En lo que sigue en tiingún momento aspiramos a la más minima exhaustividad histórica; nos moveremos más bien en el campo de los «modelos» o en una zona próxima a los «tipos ideales» de Weber. Como análisis más profundo de su evolución histórica, sigue siendo imprescindible el libro de Cohen y Arato (1992); mâs esquemáticamente también V. Pérez-Díaz (1994: 95 y ss.); en algunos capítulos de J. Keane (1992), o en el propio texto ya citado de Taylor.

${ }^{2}$ A este respecto véase la sistematización de este enfoque aliberal» en R. del Águila (1995), si bien aquî se contrapone a un modelo «demócrata». 
de definir la sociedad con independencia de su constitución política. Contrariamente a los modelos clásicos, Montesquieu subrayó, sin embargo, una continuidad entre el Estado propiamente dicho y el individuo, que estaba mediada por los «cuerpos intermedios». L'état civil incorporaría, pues, a las «sociedades" o «comunidades sociales» estructuradas jerárquicamente, que, como correspondía a la nobleza en el Antiguo Régimen, hacían de tampón entre el poder del Estado y el pueblo llano y contribuían a garantizar la libertad o, cuando menos, a evitar el despotismo. La propia ambigüedad del planteamiento de Montesquieu a la hora de entender la mediación entre sociedad civil y Estado, así como su excesiva dependencia implícita de la estructura estamental, hace que encontremos un mejor representante de este modelo en Tocqueville ${ }^{3}$. Con gran sagacidad supo detectar, en efecto, el peligro que para el mantenimiento y el desarrollo de la libertad — pero también para la propia integración socialsuponía la huída del ámbito de lo público y el refugio solipsista en la esfera privada. En Tocqueville, los cuerpos intermedios de Montesquicu son reemplazados por un fuerte asociacionismo público y privado, por eficaces y activas formas de democracia local y comunitaria y determinadas orientaciones religiosas y civiles - los «hábitos del corazón»-, que permitían cerrar el paso a la siempre presente amenaza del «despotismo administrativo». Este rico mundo asociativo no se reconduce, sin cmbargo, a una dimensión ajena al mundo político, sino que se constituye en la misma infraestructura de la política.

Por último podemos encontrarnos con un modelo intermedio entre ambas concepciones, que aparece representado por Hegel. El problcma hegcliano consiste en tratar de "superar" (en el sentido de Aufhebung) las deficicncias de la sociedad civil en el Estado. Así, por un lado, reconoce - en la línea del modelo L.- la autonomía del ámbito social como «sistema de las necesidades", que abarca también al sistema cconómico; por otro, sin embargo, se le nicga su autosuficiencia y se reclama su dependencia última del Estado, con lo cual se hallaría aquí más próximo al modelo $\mathrm{M}$. Como en Tocqueville, el problema de fondo lo constituye la integración social y normativa de individuos aislados, emancipados ya de los vínculos sociales tradicionales, que en la sociedad civil van a encontrar algo así como su «segunda familia». La diferencia con respecto a la familia propiamente dicha, es que en la sociedad civil la integración no responde a ataduras cuasibiológicas, sentimentales o mecánicas, sino a vínculos racionales y conscientes entre las personas, que se complementan entre sí - «detrás de sus espaldas»- gracias a los ciegos mecanismos del mercado 4 . Dentro de éste, «los distintos intereses de productores y consumidores (...) producen por sí mismos la relación correcta en la totalidad» (1976: § 236);

\footnotetext{
"Así lo parece reconocer también Ch. Taylor (1995: 221).

* No se deja de llamar la atención la reacción que provoca en Cohen y Arato la exclusión de la familia del concepto de sociedad civil hegeliano, tema al que dedican una discusión que, a nuestro juicio, está excesivamente mediada por nuestra percepción actual del problema (vêanse pp. 628 y ss.)
} 
los varios intereses egoístas se coordinan en una generalidad. La sociedad civil sirve de nexo entre el individuo — «fin en sí mismo» y solamente sujeto a los contratos y el derecho privado- y la sociedad global; contiene al sistema económico y a la cultura y eticidad común, y sirve a la vez de puente para integrar lo concreto en la totalidad. Pero la satisfacción de necesidades e intereses individuales únicamente puede realizarse dentro de una eticidad o Sittlichkeit unitaria - fuente, en definitiva, de la unidad social-, que sólo está en condiciones de aportar y garantizar el Estado. De esta forma se resuelve de un solo golpe el problema de la anomia y la «soledad» del individuo moderno, los requisitos de la autonomía y el libre arbitrio del hombre burgués y, por último, el de la eficacia del Derecho.

El interés y los fines egoístas necesitan ser "reconducidos a lo universal» (ibid.), deben someterse a una "regulación consciente» que esté por encima de ellos. La inmensa capacidad de la sociedad civil y el mercado para satisfacer la autonomía individual y acrecentar la riqueza y la industria tiene su efecto negativo en la exclusión de sus beneficios a un amplio sector de la población, que se ve abocado a la marginalidad y la depauperación ${ }^{5}$. En clara contraposición a la perspectiva prominente entre los autores de la flustración escocesa, Hegel no ignora las tendencias antagónicas de la sociedad civil burguesa («ibürgerliche Gesellschaft!») ${ }^{6}$. La sugerencia - «especialmente en Escocia»- de «abandonar a los pobres a su suerte y condenarlos a la mendicidad callejera» (1976: $\$ 245$ ), es inaceptable para nuestro autor, que prevé como correctivo a un Estado regulador con capacidad para imponerse sobre una sociedad civil excesivamente mediada por la promoción del interés propio y la ausencia «explícita» y consciente de una integración normativa unitaria. Éste es un recurso que la sociedad civil es incapaz de producir por sí misma. De ahí la conocida descripción hegeliana del Estado como expresión de la «Idea ética» (sittliche Idee) que tiene su origen en la voluntad explícita de salvaguardar la unidad de los ciudadanos. Reducir el Estado, al modo liberal, a la mera garantía de la libertad personal y la seguridad equivaldría a reconocer el interés de cada individuo «como el fin último por el que están unidos» (1976: \$258). El objeto de la voluntad estatal no puede ser sino «la unión como tal», que constituye el "verdadero contenido y fin» que permite a los ciudadanos llevar una vida en común; frente a la suma cirracional» de las voluntades individuales - de los «muchos como aislados»- que únicamente puede aspirar a conformar una «masa amorfa», se postula la "racionalidad de la voluntad» que encarna el Estado (ibid. y $\$ 303$ ).

s Se acrecienta la división y limitación del trabajo particular $\vec{y}$, por tanto, la dependencia y la miseria del estamento ligado a ese trabajo, agregándose la insuficiencia de la capacidad y del goce de las otras libertades, especialmente de las ventajas espirituales de la sociedad civils (1976: 243).

VÉanse $\$ 236$ y ss. 
El gran logro del planteamiento hegeliano reside en haber asentado - bien es cierto que en clave dialéctica- las diferencias decisivas entre los diferentes elementos o entidades sociales, que después habrán de ser conjugados en toda la tradición intelectual europea ${ }^{7}$. Ya sea para negar toda autonomía al Estado o a lo «civil», y reconducir toda la carga de la explicación del orden social y sus elementos a los procesos socio-económicos (Marx), ya para, en la anticipadora concepción de Gramsci, buscar un hueco a la sociedad civil entre la estructura cconómica y cl Estado ${ }^{8}$, o incluso, en la línea de los posicionamientos socialdemocráticos, recuperar el papel integrador del Estado hegeliano. La introducción de un «modelo $\mathrm{H}$.» -como mero punto de referenciaserviría para acoger conceptualmente, una vez «puesto sobre sus pies», a las concepciones marxistas, y es útil también para integrar en la discusión a importantes teorías comunitaristas. Por otra parte, sin embargo, no es fácil distinguir entre el modelo M. y un supuesto modelo $\mathrm{H}$. La diferencia puede que resida en la separación que menciona V. Pérez-Díaz entre teorías de la sociedad civil «centradas-en-la-sociedad" y las «estatistas» o "centradas-en-el-Estado" ${ }^{\text {? }}$ (1993: pp. 95 y ss.). A estas últimas, de provinencia no exclusivamente hegeliana, les imputa el haber dotado al Estado de una «dimensión moral», y tuvieron como consecuencia, en primer lugar, el «haber hecho al Estado responsable de la defensa de un nuevo principio de identidad colectiva (el nacionalismo) en un mundo de naciones-estado en competencia. En segundo lugar, hicieron al estado responsable de la creación de una comunidad de ciudadanos, y de una esfera pública donde éstos pudieran encontrarse (casi) en pie de igualdad con sus gobernantes ${ }^{10}$. En tercer lugar, hicieron al Estado responsable de la prosperidad económica y de la integración de la sociedad; o, para emplear un término del siglo $\mathrm{xx}$, le hicieron responsable de la "modernización" del país» (1993: 94).

Ninguna de estas teorias centradas-en-el-Estado es hoy compatible con una teoría de la sociedad civil propiamente dicha. De hecho, to que inspira la actual reivindicación de la sociedad civil es, precisamente, la necesidad de evitar reconocer al Estado toda centralidad en la organización e impulsión de la vida buena, desbancarle de todo protagonismo y otorgar éste a la sociedad. Todas ellas comparten, pues, un impulso de «descentralización» del Estado,

\footnotetext{
"Dice explícitamente: «La sociedad civil es la diferencia que se introduce entre el Estado y la familia, aun cuando su perfeccionamiento se produzca después con el del Estado; pues, en tanto quc diferencia, presupone al Estado, cuya independencia requiere para poder subsistir» (Hegel, 1976: \$ 182, adición).

"El gran avance que, aporta la teoría de la sociedad civil de Gramsci consistirá en separar por vez primera la sociedad civil no sólo del Estado, sino de la estructura económica, algo que hoy está generalizado entre las concepciones "posmanxistas» actuales de la sociedad civil, como es el caso de la propia de Cohen y Arato. Para comprender en sus justos términos la teoría de este autor es ya imprescindible el libro de S. Kebir (1991).

"Bien es cierto que V. Pérez-Díaz, que se adthiere claramente a la primera corriente, escribe Estado con minúscula.

"Este autor parece referirse aquí a la tradición russeauniana, a la que Taylor, como ya vimos, prefiere reconducir al modelo $\mathrm{L}$.
} 
al que se contrapone la correspondiente sensibilización por las formas de organización y auto-organización no estatales. Divergen entre sí en la distinta evaluación de sus diferenciaciones internas, y en la forma en la que la sociedad civil se conecta al Estado. Pero sobre todo, en el diferente énfasis que ponen sobre el proceso democrático o los mecanismos de integración social y política, más marcado en estos dos casos en aquellas que están en la órbita del modelo M. Con independencia de que luego entremos en mayores matizaciones, y por cerrar provisionalmente esta sección, cabe presentar ya algunas definiciones contemporáneas de la sociedad civil.

La versión más nítida del modelo L. está representada en nuestros días por las teorias que generalmente se califican de «neoliberales», y que mantienen, como es conocido, los rasgos que arriba mencionábamos al referimos a este modelo. Dentro de esta órbita, pero con peculiaridades propias, hay que conceptuar a la obra de John Gray, quien ofrece una definición relativamente convencional de lo que sea la sociedad civil, pero a la que luego carga de matizaciones, que no serían compartidas por otros representantes de esta corriente. Sociedad civil scría «aquella csfera de instituciones autónomas, protegida por el estado de derecho (rule of law), dentro de la cual individuos y comunidades que poseen valores y credos divergentes pueden convivir en paz» (1993: 157) ". En ésta, la dimensión de integración del pluralismo social se acentúa mucho más que el proceso democrático propiamente dicho. El sistema político en general acaba teniendo al final una relevancia puramente secundaria, ya que para el nacimiento y la pervivencia de la sociedad civil se requieren una serie de condiciones políticas mínimas, entre las que no figuran siquiera algunas instituciones básicas y fundamentales de la democracia liberal, como, por ejemplo, un sistema de auténtica representación parlamentaria. Aparte de sus diferentes manifestaciones históricas, «sociedad civil» vendría a ser la forma de organización surgida espontáneamente en un mundo caracterizado por la existencia de concepciones valorativas plurales e inconmensurables, que harian inviable el establecimiento de un sistema de principios políticos sostenidos a partir de un supuesto consenso moral general. El «liberalismo agonístico» ${ }^{12}$ que propugna ha renunciado ya a la posibilidad de integrar esta pluralidad a partir de visiones normativas unitarias y universalistas al modo rawlsiano. Influido por la tesis berliniana de la inconmensurabilidad de los valores y la centralidad del pluralismo, a la que suelda la propia visión de la political association de Oakeshott, acaba concluyendo que lo único que «está vivo» del liberalismo ${ }^{13} \mathrm{es}$ precisamente su idea de la sociedad civil. Una sociedad civil "contextualizada», sujeta a tradiciones morales y políticas diversas ${ }^{14}$, que úni-

"En un autor tan inquicto y cambiante como Gray, esta definición pucde no reflejar ya su última línea de pensamiento.

12 Véase, del mismo autor, "Agonistic Liberalism", en 1995.

${ }^{13}$ Véase su articulo «What is dead and what is living in liberalism?», en 1993, pp. 283-328, particularmente pp. 314 y ss.

${ }_{14}$ Así, hay sociedades civiles kautoritarias», de países asiáticos como Corea del Sur, Hong Kong o Taiwan, por ejemplo, que funcionan como tales sin poseer la cultura moral del individualismo. 
camente requiere para poder funcionar de un Estado neutro y tolerante respecto a las distintas concepciones del bien, la institución de la igualdad ante la ley garantizada por el rule of law, un sistema de propiedad privada individual y/o comunal, libertad contractual y las libertades civiles de asociación, conciencia, movimiento y expresión. Este transfondo garantiza ya, sin necesidad de la preexistencia de las instituciones económicas o la moral individualista occidental, el modus vivendi necesario para asentar una «cultura de la libertad», una cultura en la que «los individuos son libres de reunirse para la consecución de intereses compartidos, pero no precisan tener un interés en común» (1993: 318). Aquí, como es obvio, no se prejuzga la existencia de una «esfera pública» más o menos conectada al sistema político, y la economia se ve como uno de los ámbitos fundamentales de la libre interacción de la sociedad civil.

Manteniendo este mismo ćnfasis sobre la pluralidad y el asociacionismo, pero desde el polo opuesto en lo relativo a la evaluación de los mecanismos de integración social y la conexión política, está el comunitarismo republicano, representado mejor que nadie por $\mathrm{M}$. Walzer. Su visión de la sociedad civil, claramente enmarcada en la línea del modelo M., es quizás excesivamente general, pero tiene la virtud de tomar en consideración todos los problemas asociados al concepto. Para él, sociedad civil sería el «espacio de la asociación humana no coercitiva, y también el conjunto de redes relacionales - formadas para favorecer a la familia, la fe, el interés y la ideología- que llenan ese espacio» (1991: 293). Es, pues, reticular y asociativa, y el fin que debería estar destinada a satisfacer no es otro que el permitir acoger los principios de la ciudadanía democrática y la participación en la vida socio-política de todos los ciudadanos, pero también la realización de la autonomía individual y la identidad nacional. M. Walzer mantiene también sus distancia respecto al liberalismo con pretensiones universalizantes, cuya acentuación de la unidad y homogeneidad sólo coadyuvaría a disciplinar la pluralidad y heterogeneidad de formas de vida, que precisamente constituyen la riqueza de nuestras sociedades. Su recuperación a través del concepto de sociedad civil significatía una "nueva valoración de las partes sobre las totalidades» (1991: 301). Aboga así a favor de «una nueva sensibilidad por lo que es local, específico, contingente»; «la vida buena está en los detalles» (1991: 304), y por hacerlo brotar a través de las redes asociativas en las que se encarama o despliega. Esto no sería posible, sin embargo, sin una mayor apertura del proceso democrático, que cumpliría dos funciones básicas: primero, «pluralizar» y diversificar el demos; $y$, en segundo lugar, fusionar la variedad resultante mediante el principio de la ciudadanía. El valor de la participación política y de la apertura constante del sistema democrático a la pluralidad tiene el efecto antes mencionado de contribuir por sí mismo a generar una identidad política común. El rol de ciudadano es uno de los muchos que puede asumir el individuo, con la importante diferencia de que el Estado no es una asociación como las otras: exige a quienes de él participan que hagan suya la perspectiva del bien común con 
independencia de sus concepciones del bien particulares. En clara oposición a la tesis de Gray que acabamos de exponer, para Walzer sociedad civil y sistema democrático se alimentan mutuamente: «sólo un Estado democrático puede crear una sociedad civil democrática; sólo una sociedad civil democrática puede crear un Estado democrático» (1991: 302). De ahí la "preeminencia práctica» que tiene la ciudadanía sobre cualquier otra adscripción. Y de ahí también la visión del Estado, no sólo como un mero marco pacificador y coordinador de la vida social, sino también como «el instrumento de la lucha utilizado para dotar de una forma determinada a la vida en común» (1991: 302).

La visión que Walzer nos ofrece del Estado lo aproxima en cierto modo al modelo hegeliano, en tanto que le concede la función de «compensar» algunas de las deficiencias más sobresalientes de la sociedad civil. La idea de que el pluralismo es «auto-suficiente y se auto-sostiene» es un mito liberal. Una sociedad civil dejada a su propia dinámica acabaria por generar «relaciones de poder radicalmente desiguales» (1991: 302). Es preciso recurrir al poder político para redistribuir recursos y apoyar y subsidiar las actividades asociativas más deseables. Pero se separa de este modelo al privar al Estado de toda substancialidad ética y de toda autonomía con respecto a la sociedad civil. El gran desafío de ésta consiste, precisamente, en conseguir que sus intereses plurales sean accesibles a las burocracias estatales; no en vano es en y a través de ella como se produce y reproduce la "civilidad». Su gran objetivo consiste, además, en una permanente labor de «descentramiento» de las actividades estatales, que habria de conseguirse mediante la asuncion de una mayor responsabilidad por parte de los ciudadanos en la mayoría de los ámbitos de la acción estatal. De lo que se trataría al final es de intentar potenciar ese proceso de retroalimentación entre Estado y sociedad civil, y no, como veremos en otras conccpciones, de acotar espacios rígidamente escindidos. Del mismo modo que habría que «socializar» la economía; no en el sentido de cambiar la estructura del sistema de propiedad, sino en el de pluralizar los agentes del mercado y, por ejemplo, limitar con la ayuda del Estado el poder de las multinacionales.

Por último, y éste es un tema al que nuestro autor ha dedicado un buen número de reflexiones, otra de las labores fundamentales de la sociedad civil habria de consistir en "pluralizar y domesticar el nacionalismo» (1991: 303). $\mathrm{Y}$ a estos efectos le va a ser también tremendamente útil su concepto de ciudadanía. En nuestra actual sociedad pluralista, y aquí Walzer se deja Ilcvar por el ejemplo norteamericano, cabría distinguir entre comunidades étnicas, cada cual con su módelo de solidaridad grupal y su propia concepción del bien, y comunidad política propiamente dicha, cuya unidad deriva del acuerdo sobre los principios políticos de la ciudadanía liberal. Esta última permite acceder a una integración normativa común gracias a los propios mecanismos de participación política; que acaban soldando las diferentes identidades étnicas a una identidad política compartida. El problema de la integración normativa 
de sociedades étnicamente plurales se disolvería así por la efcctiva existencia de posibilidades institucionalizadas de partícipación democrática, así como la de una sociedad civil capaz de acoger una ilimitada variedad de identidades históricas. El conflicto entre ethnos y demos se resolvería si fuéramos capaces de generar una identidad política que no fuera tan «sustancial» como para que en ella no pudieran reconocerse los grupos minoritarios, ni tan débil como para impedir la integración política y la solidaridad ${ }^{15}$.

Con todo lo sugerente que es esta concepción de la sociedad civil, al final despide importantes dosis de voluntarismo democrático. Walzer no ignora las dificultades efectivas de generalizar el ideal del ciudadano crítico y activo, permanentemente dedicado al enjuiciamiento de la realidad social y política y activo en grupos políticos. El papel de ciudadano es uno entre otros. Piensa, sin embargo, y esto es algo generalizado entre las concepciones de la sociedad civil más democráticas, que un «asociacionismo crítico» en cualesquiera de los ámbitos sociales puede sentar las bases para reforzar su apertura al pluralismo social y la acción colectiva. Sería un proyecto modesto y realista, ni tan heroico o ambicioso como los que se asientan sobre sujetos tales como el «demos», la «clase trabajadora» o los «consumidores de la nación», pero mucho más efectivo para articular en torno a él una verdadera transformación en los ámbitos del Estado, la economía u otras esferas sociales.

El punto en el que disienten con él las teorías de la sociedad civil que se autocalifican de «postmarxistas» - como la de Cohen y Arato- es, sin embargo, el relativo a la posibilidad de trasladar este asociacionismo de modo eficaz al ámbito de la economía y el Estado. Frente al asociacionismo de Walzer, que se introduce en todos los rescoldos sociales, Cohen y Arato - siguiendo explícitamente a Habermas ${ }^{16}$ - llevan hasta sus últimas consecuencias las diferencias que el autor alemán establecc cntre «sistema» y «mundo de la vida», reservando como el lugar propio de la sociedad civil este último espacio regulado por la fuerza comunicativa de la comprensión social y la solidaridad. Su «radicalismo" -que evita caer en el trilema de las tres erres: reforma, revolución o resignación - sería «autolimitado» en tanto que su proyecto para la «defensa y democratización de la sociedad civil acepta la diferenciación estructural y reconoce la integridad de los sistemas políticos y económicos» (1992: 493). Así pues, para buscarle un espacio a la sociedad civil recurren a la propuesta gramsciana de ubicarla entre la economía y el Estado. Estaria compuesta «por la esfera intima (la familia en particular), la esfera de las asociaciones (especialmente las asociaciones voluntarias), los movimientos sociales, y las formas

${ }^{15}$ Para una visión más general de esta discusión, véase $\mathrm{M}$. Walzer (1992 y 1993).

${ }^{16}$ Por obvios problemas de calendario -Civil Society and Political Theory (1992) se elabord antes de la aparición de Faktizität und Geltung (1992) - la obra de Habermas que incorporan es fundamentalmente su Theorie des kommunikativen Handelns y otros escritos éticos y políticos, que son reelaborados a efectos de articular a partir de ellos una teoría de la sociedad civil. 
de comunicación pública" (1992: ix) ${ }^{17}$. Como en M. Walzer, el recurso a la sociedad civil sirve aquí para satisfacer la doble finalidad de, por un lado, insuflar una - «aunque sea mínima» o «débil»- «identidad colectiva» (1992: 369 ), que no tiene por qué sustentarse sobre una concepción concreta de la vida buena; $y$, por otro, designar al sujeto activo de un proceso democrático plural. Este sujeto se presenta en su relación con el Estado más bajo el símil de un «cerco» o asedio de la política burocratizada que bajo la perspectiva de la porosidad, la interpenetración o la retroalimentación que se ajusta más a la propuesta de Walzer. La "regeneración moral» permanente que representa el activismo que se produce en los espacios de la sociedad civil, y su plena confianza en una casi completa rehabilitación y «descolonización» de los mismos, contrasta con un cierto pesimismo hacia la posibilidad de abrir los espacios del «sistema» a la racionalidad comunicativa. El problema no consiste, pues, tanto en tomar dichos espacios al asalto democrático, cuanto en despejar la perniciosa influencia que ejercen sobre una sociedad civil asentada en el mundo de la vida (véanse pp. 448 y ss.). De ahí su acentuación de la «utopía de la difercnciación», que, en la cita que reproducen de Habermas, permitiría «abrir el horizonte utópico de la sociedad civil» en el que pudieran asentarse las esferas de acción "formalmente organizadas» del bourgeois (economía y aparato cstatal), y el «mundo postradicional» del homme y el citoyen (1992: 452).

Antes de dejar provisionalmente esta teoría, merece la pena enlazarla a la discusión antcrior. ¿En cuál de los modelos clásicos mencionados -el $\mathbf{L}$. y el M.- encuentra un mcjor acomodo? No es una pregunta que posea fácil respuesta. Su separación del ámbito económico de la sociedad civil, así como su enfatización de un asociacionismo libre y politizado y la reivindicación de la vida pública, parecen acercarla al modelo M. La visión del Estado como una entidad reificada y sujeta a permanente control del público, por el contrario, favorece una explicación en la línea del modelo L. También su reiterada insistencia en el principio de legalidad y en su visión de los derechos fundamentales como el sprincipio de organización de una sociedad civil» (1992: 442) favorecería esta última opción, que se muestra como la más razonable. Desde luego, lo que parece evidente es un alejamiento claro del modelo $H$., dada la imposibilidad de imaginar al Estado en una interacción comunicativa con la sociedad y, mucho menos aún, como capaz de aglutinarla o integrarla normativamente. El proceso sería exactamente inverso al imaginado por Hegel, ya que de lo que se trata aquí es, precisamente, de evitar que la espontaneidad que brota de la libre comunicación en la socicdad civil pueda verse contaminada por los procesos

${ }^{17}$ Consecuentemente poseeria los siguientes componentes:

«1) Pluralidad: familias, grupos informales y asociaciones voluntarias cuya pluralidad y autonomía permite una pluralidad de formas de vida; 2) Publicidad: instituciones de la cultura y la comunicación; 3) Privacidad: ún ámbito del autodesarrollo y la elección moral; 4) Legalidad: estructuras de leyes generales y derechos fundamentales necesarios para demarcar la pluralidad, privacidad y publicidad de, al menos, el Estado y, tendencialmente, la economia» (1992: 346). 
de administración y juridificación del Estado $\longrightarrow$ la reificación económica-. Salvadas las distancias, y exceptuando su labor en la garantía de la eficacia de los derechos, el papel «redentor» de la sociedad civil que cumplía el Estado hegeliano le corresponde aquí a la sociedad civil respecto del Estado y sus dinámicas "perversas». Su pretensión por reconciliar las exigencias del liberalismo clásico con las de la democracia radical queda así, a la postre, insatisfecha. Faltan por desarrollar sobre todo los canales de mediación o «interpenetración" entre Estado y sociedad ${ }^{18}$, como luego haria con mayor éxito J. Habermas (1992), quien a través del derecho creado siguiendo canales de acción democrática busca penetrar en los intersticios del sistema estatal para desde él proyectar luego de vuelta toda la fuerza comunicativa hacia la socie$\mathrm{dad}^{19}$. Y falta por delimitar también el espacio exacto que ocupa la esfera pública como ámbito de intersección entre lo público y lo privado, y lo social y lo estatal, Tanta diferenciación resulta, al fin, en un juego conceptual en el que este sujeto colectivo del libre asociacionismo, con su autonomía respecto de los dos grandes sistemas de la economía y el Estado, no se sabe bien si está dentro o fuera del sistema político, o si lo está de modo permanente u ocasional. Lo que parece claro es que estas asociaciones operan como algo próximo a «instituciones no institucionalizadas». «Instituciones», en tanto que su funcionamiento está amparado y reconocido por el mismo derecho; no institucionalizadas por cuanto que derivan su fuerza de la propia voluntariedad, autonomía y una forma de organización comunicativa.

\section{II}

No es preciso ser un luhmanniano para reconocer que toda descripción comporta la introducción de distinciones o «diferencias» para designar unas cosas, y no otras, que quedan sin delimitar. Observar equivale a discriminar, presupone la incorporación de un sistema de diferencias a partir del cual descomponemos la inabarcable e irrealizable unidad del mundo. Toda la explicación aparece así mediada al final por los filtros que estas distinciones insertan entre el observador y la realidad observada. Y una observación/descripción será tanto mấs «válida» que otra cuanto mayor sea el «mundo» que es capaz de concentrar en la observación. En cualquicr teoría de la sociedad civil, pero también en casi cualquier reflexión sobre la política, no podemos dejar de manejarnos con dualismos polarizados como el de Estado y sociedad, que al final acaban por codificar nuestra mirada y, consecuentemente, nos facilitan la visión de determinados aspectos de la realidad a la vez que nos ocultan otros. No está

1E Por otra parte, exactamente igual que ocurre en los trabajos de $\mathrm{M}$. Walzer; él al menos se limita a la reflexión fïlosófica y no tiene ninguna pretensión por conectarla a una rigurosa teoria social.

${ }^{19}$ A este respecto véase F. Vallespin (1996). 
claro, en cualquier caso, en contra de las afirmaciones de Luhmann, que otras «diferencias» alternativas - como su propia distinción entre sistema/entorno, por ejemplo- sean más aprovechables, más capaces de reducirnos la complejidad de la observación del mundo político. Sobre todo cuando las descripciones que deseamos reflejar, como en el caso de las teorías de la sociedad civil, buscan dar cobijo a una teoría de la acción social y están imbuidas de elementos normativos. Por otra parte, nuestra mirada sobre la realidad política no puede escaparse de la herencia del liberalismo, con su indiscutible «arte de las diferencias», su capacidad para hacer distinciones entre sectores o ámbitos, tanto dentro del Estado y de la sociedad como en la relación entre ellos. Ni puede eludir tampoco el correlativo predominio de una metáfora espacial que delimita permanente e incesantemente «territorios», áreas o demarcaciones, cada una con su sistema de racionalidad y sus códigos, sus «fronteras» e interpenetraciones. Metáfora a la que necesariamente hay que cruzar la dimensión temporal, cvolutiva, el problema del discernimiento de las pautas del cambio social, que contribuye a desdibujar y nos obliga a volver a trazar y a redefinir los «espacios» previamente objetivados. Asimismo, sobre estas dos dimensiones se proyectan también las dificultades derivadas de intentar atrapar tanto los procesos materiales, causales, como la difícil dimensión de lo simbólico, cxpresivo o «espiritual».

Obviamente, no es éste el lugar para penetrar en este conjunto de problemas epistemológicos. Si los traemos a colación es, sin embargo, para intentar poner a prueba algunas de estas distinciones en su utilización por las actuales teorías de la sociedad civil. A este respecto, lo que más llama la atención en esta literatura es la aparente facilidad con la que se traza la distinción entre Estado y sociedad. Casi parece como si esta frontera apareciera delimitada por mojones bien perceptibles a simple vista. La causa de este confinamiento del Estado dentro de una demarcación precisa obedece en parte a ese mismo impulso normativo que guía a las teorías de la sociedad civil y al que ya hicimos referencia al comienzo de este trabajo. V. Pérez-Díaz nos lo dice explícitamente cuando afirma que «señalar los límites del estado es, por tanto, mostrar el potencial de la sociedad civil» (1993: 135). En cierto modo, entonces, una de las funciones de estas teorías estribaría en acotar cuáles son las funciones que competen al Estado para a partir de ahí dejar que sea la propia auto-organización social la que cubra los espacios vacantes. Pero el problema reside precisamente en esta definición de funciones. Algunas no son demasiado difíciles de especificar, como por ejemplo, si el Estado debe o no prestar determinados servicios, mientras que la definición de otras resulta ya mucho más problemática. En este sentido, y por seguir con V. Pérez-Díaz, se nos mencionan, por ejemplo, funciones tales como la integración social o la contribución del Estado al sentimiento de la identidad colectiva (véanse, 1993: 82 y ss.) ¿Cómo «acotar» los límites de la acción del Estado en la satisfacción de estas funciones?; ¿cómo saber cuándo está capacitada la sociedad civil para proveerlas por sí misma, en parte 
o en su totalidad?; y, sobre todo, ¿cómo se relacionan entre sí, cuál es la conexión o interdependencia entre unas y otras funciones? ¿Acaso no existe una relación entre los mecanismos de integración social y normativa de una sociedad y la prestación pública de determinados servicios sociales? Tan importante como trazar las fronteras del Estado parece entonces la necesidad de restringir algunos subcampos o algunas dinámicas de la sociedad civil -en su concepción liberal, al menos-, como aquello que V. Pérez-Díaz califica como «la experimentación institucional con los mercados abiertos». Pero áquién estaría capacitado para desarrollar esta labor, y cómo habría de hacerse? Este mismo autor reconduce este problema a la ciudadanía, a la capacidad de los agentes sociales para enjuiciar y atribuir «legitimidad sustantiva» a las disposiciones estatales y a la función del Estado en la resolución de problemas fundamentales de la socicdad $(1993 ; 83)$. En un sistema democrático es evidente que el enjuiciamiento último de la actividad estatal debe recaer sobre la ciudadanía. Pero no es menos cierto que ésta se encuentra sometida a importantes restricciones en su capacidad de percepción, si no de la política «institucional», sí al menos de las lógicas de procesos sociales «ciegos», auto-organizados, sistémicos, como son los que caracterizan a la economia y el derecho. En esto sí lleva razón Luhmann, y Habermas y otros, como Cohen y Arato, así se to han reconocido. No es, pues, arbitraria la delimitación de un espacio autónomo para los subsistemas estatal y político, y éste es el punto en el que cobra relevancia el desgajamiento de estos campos del ámbito de una sociedad civil conceptuada ante todo en términos comunicativos. Y explica también la relativa impotencia del Estado para «dirigir» procesos sociales que responden a sus propias lógicas, y reaccionan ante cualquier interfercncia con una importante merma de sus potenciales prestaciones ${ }^{20}$. No podemos dejar de estar tampoco con Habermas autor cuando sostiene que no es posible una «atribución administrativa del sentido», y que las tarcas de integración normativa y la repro* ducción simbólica - la transmisión cultural, la integración cultural y la socialización- deben encarnarse en el mundo de la vida.

El problema de los límites entre Estado y sociedad puede reconducirsc así a otra «diferencia», aquella entre sistema y mundo de la vida ${ }^{21}$, e intentar haccrla fructificar como base de observación y descripción de la realidad política. Distinguir entre mecanismos de coordinación indirecta o kinterdependencias no-coordinadas» y relaciones intencionales y «comunicativas» propiamente dichas, así como acercarse a su interrelación, no sólo sirve para ponernos ante la vista las «amenazas» que se cicrnen sobre determinados ámbitos sociales encargados de satisfacer determinadas funciones -como, por ejemplo, la repro-

* Véase a este respecto el fundamental artículo de T. Schapf (1991).

${ }^{21}$ La integración sistémica se refiere, en términos generales, a la efectividad de las relaciones, regularidades y leyes funcionales que, en principio, al menos, se presentan como independientes de la voluntad de los que en ellas participan - las leyes del mercado, por ejemplo. La integración social, por su parte, presupone un comportaniento mediado subjetivamente y que se mantiene a través del seguimiento de reglas normativas. 
ducción simbólica y su implicación directa sobre la «crisis de sentido» y anomia social-, sino que nos desvela todo un complejo mundo de conexiones y lazos sociales diversos. Pero esta misma complejidad tiene un efecto recursivo, ya que nos devuelve después un mundo aún más complejo, que en una regresión infinita contribuye a dejarnos permanentemente insatisfechos. $Y$, sobre todo, nos hace dudar al final del sentido de una excesiva «diferenciación» de espacios y esferas sociales, formas de racionalidad, lógicas, códigos, etc., muchos de los cuales - la mayoría- únicamente son perceptibles para nosotros, los observadores, dentro, además, de nuestras propias definiciones convencionales. El efecto inmediato es la desconfianza hacia diferenciaciones cxcesivas, que son también dificiles de verificar, y que es algo que habremos de saber sobrellevar junto con el malestar y la insatisfacción por las simplificaciones.

Un ejemplo claro es esta escisión — antes aludida - del ámbito de la economía respecto de la sociedad civil. Excluirla cquivale a afirmar que efectivamente hay un «espacio» - ¿dónde? - libre de interferencias «económicas» de uno u otro tipo, o que dentro de la multiplicidad de actores sociales que hacen acto de presencia en la esfera pública y constituyen el pluralismo asociativo es posible diferenciar claramente entre uno dirigido al interés público, «voluntario", "libre" y "comunicativo» y otro "privado», guiado por intereses no generalizables ni susceptibles de serlo. Basta con contemplar mínimamente el mundo que nos rodea para llegar a la conclusión de que esta labor de diferenciación es, cuando menos, titánica, Otro tanto ocurre con el mismo concepto de «espacio o csfera pública», y el mismo Habermas se vio obligado a matizar las elevadas esperanzas que en él habían puesto Cohen y Arato, y a advertir que su «elemento más sobresaliente» eran «los medios de comunicación de masas y las grandes agencias», claramente situados del lado de intereses comerciales, así como toda la parafernalia pública instituida por la propaganda y publicidad de los partidos y asociaciones diversas (1992: 444). Pero, por otro lado, si extendemos la dimensión semántica de sociedad civil a esa esfera apenas diferenciada que media entre el individuo y el Estado, nos arriesgamos a perder toda la fuerza definitoria del concepto. ¿Qué diferencias habria entonces entre una teoría de la sociedad civil y las teorías de la democracia pluralista tan generalizadas en los años cincuenta y sesenta? Esto es algo perfectamente perceptible tras la lectura del claro y sintético articulo de L. Daimond (1994), por poner un ejemplo, que tiene la gran virtud de aligerar la tensión de cualquier sufrido lector de Cohen y Arato, pero cuya descripción de la sociedad civil no hace sino abundar en las funciones mediadoras entre un público plural, articulado en una multiplicidad de grupos y asociaciones, y el entramado estatal. Y como ocurre en casi todas las teorías de esta naturaleza, falta una mayor y mejor descripción de la forma en la que desde el otro polo, el Estado, se acoge esa pluralidad. Articular una consecuente teoría de la sociedad civil parece exigir una ponderada atención a estas dos dimensiones, sin que esto tenga por qué prejuzgar su carácter de más o menos «centrada» 
en el Estado o la sociedad. La ventaja que de ahí se deriva consiste principalmente en permitir centrar la dimensión política del fenómeno de la sociedad civil.

Esto es precisamente lo que nos encontramos en el excelente libro de B. Peters (1993: 329 y ss.), donde introduce un curioso e inteligente «modelo de esclusas», que es recogido luego también por J. Habermas en su última obra (1992) ${ }^{22}$. Consistiría fundamentalmente en la distinción entre un «centro» y una «periferia» dentro del sistema político. El centro estaría compuesto por lo que cabría calificar como la política «institucional», que abarcaría al gobierno y la Administración, los tribunales de justicia y el sistema representativo y electoral (las cámaras parlamentarias, las elecciones políticas, la competencia interpartidista; etc.). El procesamiento de las decisiones funcionaría aquí siguiendo inercias, "nutinas» $y$, en general, movimientos pautados que, sin embargo, obligan a que sus operaciones y procesos pasen por los estrechos canales de todo un sistema de esclusas, que se interponen en las relaciones entre los diferentes órganos e instituciones. La periferia estaría constituida por la acción de una «esfera pública» integrada por todo tipo de grupos y organizaciones sociales, capaces de conformar, alterar e impulsar la opinión del público, y que a su vez ejerce influencia y condiciona decisivamente las acciones del «centro».

Desde luego, las diferencias entre una y otra dimensión saltan a la vista: en el centro nos encontramos con la auténtica capacidad de adoptar decisiones políticas vinculantes, y donde cada uno de sus órganos tiene sus prerrogativas y relaciones claramente tipificadas. En la periferia impera, por el contrario, un sujeto público, descentrado, informal, descompuesto en una serie de redes organizativas, que a lo más que puede aspirar es a intentar imponer su influencia. Aun así, su acción fundamental estriba en intentar condicionar la acción del centro del sistema político; en evitar que éste pueda funcionar a espaldas de los flujos de comunicación provinientes de la esfera pública y la sociedad civil.

Este modelo recuerda a la conocida explicación del funcionamiento del proceso político desde el esquema de las tablas in-put/out-put, con la importante diferencia de que aquí se rompe la radical diferenciación que éste establecía entre un sistema social, que «introducía» temas y otorgaba legitimidad al sistema político, y una esfera política autónoma encargada de «producir» decisiones que afectaban a un determinado «entorno». En el modelo de Peters y Habermas, y en esto coinciden con recientes elaboraciones politológicas, la diferencia entre un sistema y otro no es radical. El proceso político se mueve aquí a través de flujos de comunicación canalizados en una multiplicidad de esclusas, que recuerdan más a la idea de continuum - entre centro y periferia- que a la de sistemas independientes interactuando. El sistema político acabaría por abarcar también a la propia sociedad civil, que mediante procesos discursivos podría

${ }^{22}$ La diferencia de fechas entre ambos libros se explica porque Habermas lo cita «en prensa». 
interferir y actuar políticamente sobre sí misma. Su gran baza es la inmensa capacidad que tiene para suscitar temas, sensibilizar y llamar la atención sobre problemas, actualizar responsabilidades políticas en el «centro», etc. En suma, para «problematizar» su acción y mantener vivo el proceso comunicativo que debe prevalecer en un sistema democrático entre la ciudadanía y los órganos institucionales, en particular sobre las cámaras representativas.

\section{III}

Este desplazamiento de los límites entre sociedad civil y Estado hacia «dentro» del sistema político nos obliga a repolitizar nuestra visión de la sociedad civil, sin por ello renunciar a subrayar su «autonomía». Significa romper con la idea de la existencia de una frontera claramente delimitada entre uno y otro ámbito, entre Estado y sociedad. Al «diferenciarse» la propia estructura intema del Estado se consigue también una comprensión mucho măs abierta de sus procesos interiores, que permite matizar y reinterpretar en mayor profundidad la idea del Estado como bloque monolítico. El modelo de las esclusas nos lo presenta más bien como una instancia «policéntrica», diferenciada, con una nítida distinción entre niveles y funciones, y con una clara localización de unidades que se abren con mayor o menor sensibilidad a los flujos provinientes de fuera del marco institucional. Es un modelo, en suma, donde el poder se puede imaginar circulando por una multiplicidad de intersticios, sin dejar fuera de la vista la fuente desde la que es bombeado y cómo después revierte sobre clla ${ }^{23}$. De hecho, la energía que parte de la "periferia» se contempla también distinguiendo entre lo que son estructuras y procesos dirigidos a la conformación de voluntades específicas, la agregación y articulación de intereses y, en general, otras exigencias que se dirigen a los procesos de decisión del «centro».

Indudablemente, adoptar esta perspectiva no equivale necesariamente a buscar una «reconciliación» con el Estado, o a optar por una teoria de la sociedad civil «centrada-en-el-Estado». Representa y busca una rcconciliación con la politica y, por tanto, no puede excluir de ésta a su dimensión institucional o verla como una ciudadela inexpugnable que obliga al correspondiente encapsulamiento de la sociedad. Somos de los que creemos que no es posible una identidad social independiente de la política, que ambas se necesitan y presuponen mutuamente, y que la reflexión sobre la sociedad civil puede y debe contribuir a lograr esta aproximación. No ignoramos que la rehabilitación de las reflexiones sobre la sociedad civil son, en efecto -como decíamos al comienzo de este trabajo-, bien expresivas no ya sólo de una cierta «crisis del Estado» en su capacidad de dirección y de integración normativa y simbólica, sino de una fatiga y desorientación de la misma política democrática. Sobre esto ha

${ }^{23}$ Un análisis lúcido de la búsqueda de una «congruencia» entre Estado y sociedad civil se encuentra en Roscnblum (1994). 
tenido una influencia decisiva la «estatalización» de los partidos políticos, la tecnocratización de los procesos de decisión política, la globalización de la economía y, en general, de todas las dinámicas y sistemas sociales; pero también fenómenos tales como la diversificación del público que se manifiesta en una comprensión de la política como "política de la vida" (life politics) (véase, Giddens, 1994), con sus nuevos procesos de individuación y las políticas de estilos de vida; asimismo, ya en el ámbito de la teoría, el abandono - para bien- de las ideologías totalizadoras, y el creciente fraccionamiento del discurso político. La consecuencia más inmediata es o bien la «fatiga civil» (M. Gauchet), la apatía política y el «retorno a lo privado»; o el salto hacia el irracionalismo político que ponen de manifiesto el crecimiento de partidos de extrema derecha o los nacionalismos; o el activismo en movimientos sociales plurales y heterogéneos. En definitiva, un paisaje marcado por el pluralismo, la diversidad y la fragmentación.

Es difícil, pues, no concluir que detrás de un concepto tan profusa como heterogéneamente interpretado como es el de sociedad civil, no se esconde sino un intento por representar como unidad a un sujeto social fraccionado y diverso, cuyas señas de identidad sólo se pueden atrapar dentro de la definición del espacio en el que actúa, y que éste, a su vez, sólo puede acotarse previa delimitación de otro u otros espacios. Esta necesidad de unificación de lo disperso y fraccionado, como se manifiesta también en la sólida presencia contemporánea de los comunitarismos, tiene sin embargo la virtud de aproximarnos a algunas de las «patologías» de nuestro sistema social y político, como son la ausencia de un sujeto democrático unitario y el problema central de la integración normativa, así como a los límites y posibilidades de conectar a la ciudadanía con el sistema político. Pero ello no tiene por qué significar el abandono de una reflexión más diferenciada y conflictual ni de una perspectiva menos reconciliada con lo existente. Puede que sea ésta la tarea que nos queda por hacer.

\section{BIBLIOGRAFIA CITADA}

ÁGUILA, Rafael del (1995): «El centauro transmoderno», en F. Vallespín (ed.), Historia de la Teoria Política, vol. VI, Madrid, Alianza.

ArÁto, A. (1981): «Civil Society vs. the State», en Telos, núm. 47.

CoHen, J./ARato, A. (1992): Civil Society and Political Theory, Cambridge, Mass./Londres, MIT Press.

DAIMOND, L. (1994): «Toward Democratic Consolidation»; en Joumal of Democracy, vol. 5,3 , pp. 4-17.

DubiEL, H. (1994): «Der entfesselte Riese? Die "zivile Gesellschaft" and die liberale Demokratie nach 1989», en K. Leggewie (ed.), Wozu Politikwissenschaft? Über das Neue in der Politik, Darmstadt, Wissenschaftliche Buchgesellschaft.

Giddens, A. (1994): Beyond Left and Right, Cambridge Polity Press. 
Gray, J. (1993): Post Liberalism: Studies in Political Thought, Londres, Routledge. - (1995): Enlightenments Wake, Londres, Routledge.

HABERMAS, J. (1992): Faktizität und Gelntng, Frankfort, Suhrkamp.

Hegel, G. W. F. (1976): Gnundlinien der Philosophie des Rechts, vol. 7 de Werke, Frankfort, Suhrkamp.

KEANE, J. (1993): Democracia y sociedad civil, Madrid: Alianza.

KEBIR, S. (1991): Antonio Gramscis Zivilgesellschaft. Alltag, Ökonomie, Kultur, Politik, Hamburgo, Verlag für das Studium der Arbeiterbewegung.

Pérez-DiAz, V. (1987): El retomo de la sociedad civil, Madrid, Instituto de Estudios Económicos.

- (1993): La primacía de la sociedad civil, Madrid, Alianza Ed.

PETERS, B. (1993): Die Integration modemer Gesellschaften, Frankfort, Suhrkamp.

ROSENBLUM, N. L. (1994): "Civil Societies: Liberalism and the Moral Uses of Pluralism», en Social Research, vol. 61, núm. 3; pp. 539-563.

SCHARPF, F. (1991); «Die Handlungsfähigkeit des Staates am Ende des zwanzigsten Jahrhunderts\%, en Politische Vierteljahresschrift, 32, pp. 621-634.

TAYLOR, Ch. (1995): «Invoking Civil Society», en Philosophical Arguments, Cambridge, Mass., Harvard University Press, pp. $204-224$.

VALleSPIN, F. (1996): «iReconciliación a través del derecho? Apostillas a Facticidad y Validez de J. Habermas», en J. A. Gimbernat (ed.), La recepción de la obra de Jürgen Habermas en España, Madrid, Siglo XXI (en prensa).

WALZER, M. (1991): "The Idea of Civil Society», en Dissent, spring, pp. 293-304.

- (1992): «The New Tribalism», en Dissent, spring.

- (1993): What it means to be an American, N. York, Marsilio 